\title{
Mycological Evaluation and Mycotoxin Contamination of Swine and Poultry Feed-Shelf Life Assessment in Makurdi, Nigeria
}

\author{
Maina $\mathrm{NM}^{1}$, Maina $\mathrm{MM}^{2 *}$, Zanna $\mathrm{MY}^{2}$, Lawani $\mathrm{MA}^{3}$ and Vinkings $\mathrm{EG}^{1}$ \\ ${ }^{1}$ Department of Biological Science, Federal University of Agriculture Makurdi, Nigeria \\ ${ }^{2}$ Department of Veterinary Microbiology, Nigeria \\ ${ }^{3}$ Center for the Control and Prevention of Zoonosis (CCPZ), Nigeria \\ *Corresponding author: Meshach Maunta Maina, Department of Veterinary Microbiology, , Nigeria
}

Submission: 酒 November 01, 2017; Published: 海 February 07, 2018

\begin{abstract}
Mycotoxin production as a result of mycotic contamination of animal feeds presents a major concern to public health. It therefore becomes imperative to generate data on the mycological contamination and potential mycotoxins production with the aim of determining suitable shelf life for swine and poultry feed. For a period of eight weeks, a total of 25 swine feed samples including five samples each of Dusa (Grain husk), Soya beans, Bone meal, Brewer's residue (Burukutu) and Rice offal and 20 poultry feeds samples including five samples each of Broiler starter, Broiler finisher, Chick mash and Layer mash were collected on a weekly basis from the University of Agriculture Makurdi (UAM) animal farm and tested immediately for Moisture Content (MC), Total Mold Count (TMC), Fungal Isolation Frequency (FIF) and Relative Density (RD). The relative abundance of mycotic load from swine feed include Aspergillus species (42.6\%), Fusarium species (36.4\%), Alternaria and Acremonium species (29.6\% each) in bone meal, brewers residue and rice offal respectively while for the poultry feed Aspergillus (38.1\%) and Penicillium species (33.3\%) in starter and finisher, Penicillium, Rhizopus and Curvularia had $27.6 \%$ in the chick mash with $20.0 \%$ of Curvulariain the layers mash. Mycotoxins detected included aflatoxin B1 and B2, ochratoxins $\mathrm{A}$ and B, patulin, sterigmatocystin, zeralenone and citrinin. Our results show the presence of mycotoxins in feed vis-a-vis deterioration in feed quality thus reducing shelf-life.
\end{abstract}

Keywords: Aspergillus; Mycotoxin; Penicillium; Poultry; Sterigmatocystin; Swine

Abbreviations: MC: Moisture Content; TMC: Total Mold Count; FIF: Fungal Isolation Frequency; RD: Relative Density; MAE: Malt Extract Agar; TLC: Thin Layer Chromatography; LOD: Limits of Determination; LOQ: Limits of Quantification

\section{Introduction}

Mycotoxin production as a result of mycotic contamination of animal feeds presents a major concern to public health due to the possible transmission of these toxic metabolites to meat, milk and animal products [1]. Mycotoxins include Aflatoxins (AFLs), OchratoxinA (OTA), Sterigmatocystin (EST), Fumonisins (FBS) and Zearalenone (ZEA) which are produce by Aspergillus spp., Penicillium spp. and Fusarium spp. in the tropics [2]. The production of these toxigenic secondary metabolites frequently occurs during the processing and storage of feed when environmental conditions such as moisture content and temperature becomes favourable for the proliferation of spoilage fungi thereby contaminating the entire food-chain from agricultural cultures to the plates of consumers [3,4]. Ingestion of mycotoxins causes unconcealed mycotoxicosis which is often associated with impairment of the immune system leading to a decrease in intake of feed, animal agility and reproductive ability. Mycotoxins have also been

incriminating in oncogenesis, mutagenesis and teratogenesis $[5,6]$. Owing to the indigenous cultural practices which encourage a high consumption of swine produce and a relatively high humidity in the study area there is a major risk factor for mycotoxin intoxication. It is imperative therefore, to generate data on the mycological contamination and potential mycotoxins production with the aim of determining suitable shelf life for swine and poultry feed in the study area.

\section{Materials and Methods}

\section{Source of samples}

A total of 25 swine feed samples including Dusa (Grain husk) (5), Soya beans (5), Bone meal (5), Brewer's residue (Burukutu)(5) and Rice offal (5) and 20 poultry feeds samples including Broiler starter (5), Broiler finisher (5), Chick mash (5) and Layer mash (5) were collected on a weekly basis for a period of eight weeks 
from the University of Agriculture (UAM) animal farm in Benue State, Nigeria. These primary samples were homogenized to form a composite sample and afterwards quartered to get $15.0 \mathrm{~g}$ laboratory samples and tested immediately for Moisture Content (MC), Total Mold Count (TMC), Fungal Isolation Frequency (FIF) and Relative Density (RD). They were preserved at 4oC for mycotoxin analysis.

\section{Moisture content analysis}

Moisture content in grams was determined using the dry weight determination method. One (1g) gram of feed sample was weighed using a sensitive weighing balance and afterwards put into a dry air oven at $1000 \mathrm{C}$ to remove available moisture for sixty minutes. Results obtained in grams from the respective samples were recorded.

\section{Mycobiota determination}

Enumeration of mycotic propagules was done using pour plating technique [7]. Ten grams of each sample was emulsified and aseptically transferred into ninety $90 \mathrm{ml}$ of $0.1 \%$ peptone water. The mixture was shaken vigorously to dislodge possible fungal propagule in the sample. Serial dilutions to $10-3$ were carried out for each sample using sterile pipette. Aliquots of one $1 \mathrm{ml}$ of $10-3$ dilution were inoculated unto Potatoe Dextrose Agar supplemented with $0.05 \mathrm{mg} / \mathrm{ml}$ chloramphenicol to inhibit opportunistic bacteria in triplicates. Fungal plates were kept at room temperature for seven days. Plates with 10-100 colonies were recorded as CFU/g. Distinctive Colonies were afterwards transferred to Malt Extract Agar (MAE) and incubated at $30^{\circ} \mathrm{C}$ for microscopic and macroscopic identification. Taxonomic identification of the different genera and species were carried according to Pitt and Hocking [7] and Klich [8]. The isolation frequency of each genus and relative density of each species were calculated as follows [1]:

$$
\mathrm{F}=(\mathrm{ns} / \mathrm{N}) \times 100 ; \mathrm{RD}(\%)=(\mathrm{ni} / \mathrm{NI}) \times 100
$$

Where $\mathrm{F}$ is the Isolation frequency, ns is the number of samples in which a particular genus occurred, $\mathrm{N}$ is the total number of samples, RD is the relative density, ni is the number of isolates of a particular genus and NI is the total number of fungal isolates obtained.

\section{Mycotoxin production}

Three genera which included Aspergillus, Fusarium and Penicillium were tested for mycotoxin production according to methodology described by Soares and Rodrigues-Amaya [9] with slight modifications. Conidial suspension for the test organisms were prepared and afterward $(100 \mu \mathrm{l})$ of each strain was inoculated into $250 \mathrm{ml}$ conical flasks containing $30 \mathrm{ml}$ of YES culture medium (2\% Yeast Extract, 15\% Sucrose) which were grown in stationary phase and incubated at $30{ }^{\circ} \mathrm{C}$ for 30 days in the dark. Aliquots $(1 \mathrm{ml})$ of each culture was then mixed with $1 \mathrm{ml}$ chloroform and centrifuged at $4000 \mathrm{~g} \times$ for $10 \mathrm{~min}$. The chloroform phase was transferred to a clean vial, evaporated to dryness and re-suspended in $0.5 \mathrm{ml}$ methanol and rapidly subjected to thin layer chromatography (TLC). The analyses were carried out in a saturated vat with the following solvent system: methanol, ethyl acetate, formic acid (60:40:0.5). Mycotoxins were detected under UV light and quantified by comparison against toxin standards ( $\lambda$ : 256 and $365 \mathrm{~nm}$ ). The Limits of Determination (LOD) and Quantification (LOQ) were 1 and $2 \mu \mathrm{g} \mathrm{L}^{-1}$.

\section{Statistical analysis}

Data were entered into Microsoft excel spread sheet and later transferred into SPSS 21 (SPSS Inc., Chicago, IL, USA) statistical software for analysis. To ensure that data were normally distributed, the transform menu function was used transform data $\log 10(\mathrm{x}+1)$. Analysis of Variance was then used to pre determine significant difference between means at $\mathrm{P}<0.05$.

\section{Results}

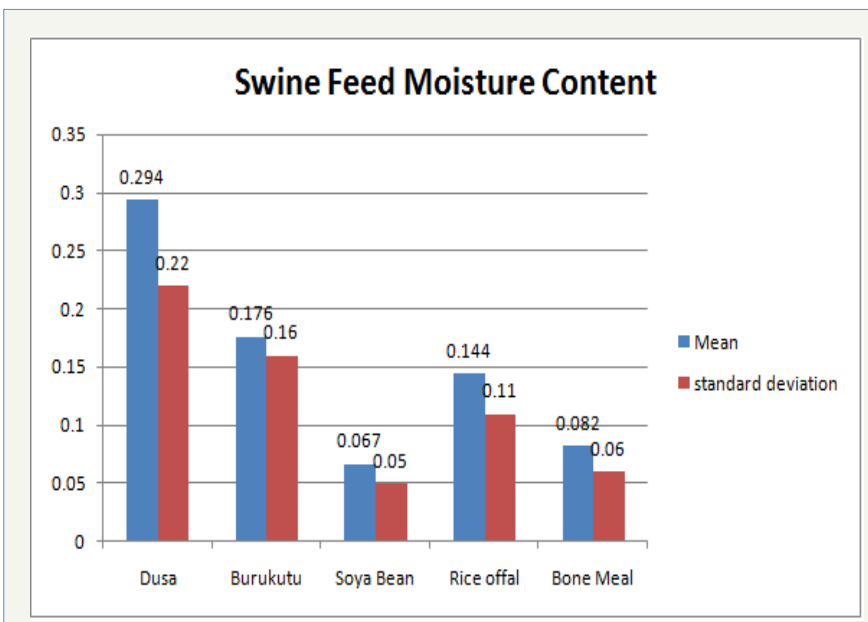

Figure 1: Swine feed moisture contents.

Figure1 Highlights the moisture content in the swine feed samples analyzed. Grain husk 'dusa' had the highest moisture content of $(0.294 \pm 0.22)$ followed by brewers residue 'burukutu' $(0.176 \pm 0.16)$, rice offal $(0.144 \pm 0.11)$, bone meal $(0.082 \pm 0.06)$ and soya beans $(0.067 \pm 0.05)$ respectively. Poultry feed samples indicated highest moisture content of $(0.214 \pm 0.13)$ in chick mash, $(0.164 \pm 0.11)$ in layer mash, $(0.131 \pm 0.12)$ in the broiler starter and $(0.086 \pm 0.07)$ in the broiler finisher feed samples respectively (Figure 2).

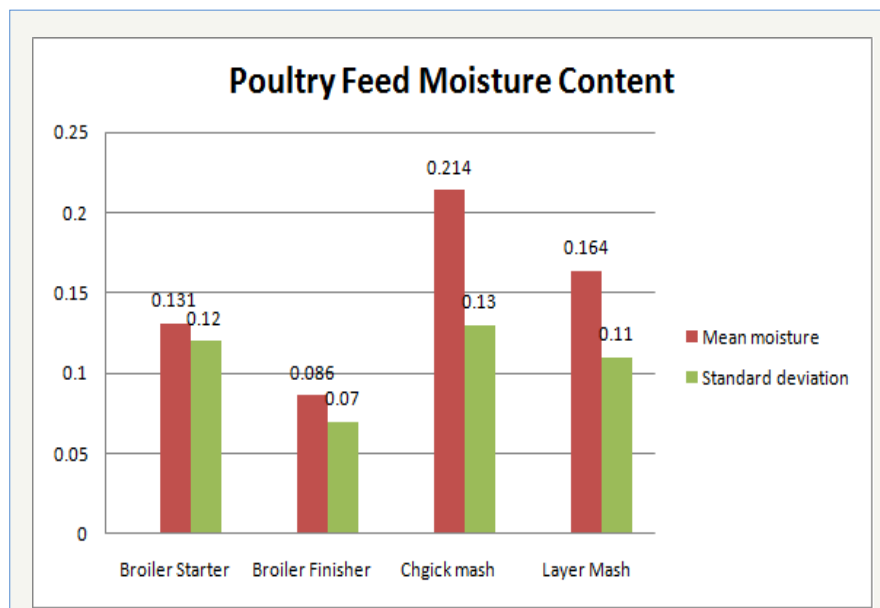

Figure 2: Poultry feed moisture content. 
Table 1 Highlights the relative abundance of the mycotic load within the swine feed samples analyzed. Aspergillus species had a relative abundance of $42.1 \%$ and $36.4 \%$ in bone meal and brewers' residue 'burukutu' feed samples respectively, followed by Fusarium species with an abundance of $36.4 \%$ in the brewers residue feed sample while Alternaria and Acremonium species had an abundance of $29.6 \%$ each in the rice offal feed however, an abundance of $8.3 \%$ was observed of Fusarium and Alternaria species in the grain residue 'dusa' feed sample.

Table 1: Mycotic Load in Swine Feed Samples (x10-3 CFU/g).

\begin{tabular}{|c|c|c|c|c|c|c|c|c|c|c|}
\hline \multirow{2}{*}{ Fungal Isolates } & \multicolumn{2}{|c|}{ Dusa } & \multicolumn{2}{c|}{ Burukutu } & \multicolumn{2}{c|}{ Soya bean } & \multicolumn{2}{c|}{ Rice offal } & \multicolumn{2}{c|}{ Bone meal } \\
\cline { 2 - 12 } & $\mathrm{RD}(\%)$ & Average & $\mathrm{RD}(\%)$ & Average & $\mathrm{RD}(\%)$ & Average & $\mathrm{RD}(\%)$ & Average & $\mathrm{RD}(\%)$ & Average \\
\hline Aspergillussp & $8(22.2)$ & $8.38 \pm 1.68$ & $8(36.4)$ & $8 \pm 2.44$ & $7(25.9)$ & $4.86 \pm 1.34$ & $0(0)$ & $8(42.1)$ & $8.5 \pm 1.77$ \\
\hline Rhizopuspp & $8(22.2)$ & $2.75 \pm 0.46$ & $0(0)$ & 0 & $3(14.3)$ & $2.57 \pm 0.57$ & $3(11.1)$ & $2.67 \pm 0.57$ & $0(0)$ & 0 \\
\hline Mucorsp & $8(22.2)$ & $4.25 \pm 2.37$ & $0(0)$ & 0 & $3(14.3)$ & $2 \pm 0.0$ & $8(29.6)$ & $6.63 \pm 2.2$ & $0(0)$ & 0 \\
\hline Peniciliumsp & $6(16.6)$ & $5.17 \pm 1.94$ & $6(27.3)$ & $6.83 \pm 0.75$ & $7(25.8)$ & $5.14 \pm 2.34$ & $0(0)$ & 0 & $3(15.8)$ & $1.67 \pm 1.115$ \\
\hline Fusariumsp & $3(8.3)$ & $4.67 \pm 3.05$ & $8(36.4)$ & $3.5 \pm 1.41$ & $0(0)$ & 0 & $0(0)$ & 0 & $0(0)$ & 0 \\
\hline Aternariasp & $3(8.3)$ & $4.33 \pm 1.53$ & $0(0)$ & 0 & $7(25.9)$ & $5.57 \pm 1.27$ & $8(29.6)$ & $10 \pm 2.20$ & $8(42.1)$ & $8.13 \pm 2.0$ \\
\hline Acermoniumsp & $0(0)$ & 0 & $0(0)$ & 0 & $0(0)$ & 0 & $8(29.6)$ & $7.0 \pm 2.4$ & $0(0)$ & 0 \\
\hline Total & $36(10)$ & $5.03 \pm 2.62$ & $22(100)$ & $6.05 \pm 2.62$ & $27(100)$ & $4.56 \pm 1.90$ & $27(100)$ & $7.30 \pm 3.02$ & $19(100)$ & $7.26 \pm 3.03$ \\
\hline
\end{tabular}

Table 2: Mycotic Loadin Poultry Feed Samples (x10-3 CFU/g).

\begin{tabular}{|c|c|c|c|c|c|c|c|c|}
\hline \multirow{2}{*}{$\begin{array}{c}\text { Fungal } \\
\text { Isolates }\end{array}$} & \multicolumn{2}{|c|}{ Broiler starter } & \multicolumn{2}{c|}{ Broiler Finisher } & \multicolumn{2}{c|}{ Layer starter } & \multicolumn{2}{c|}{ Layers mash } \\
\cline { 2 - 9 } & $\mathbf{R D}(\%)$ & Average & RD (\%) & Average & RD (\%) & Average & RD (\%) & Average \\
\hline Aspergillussp & $8(38.1)$ & $8.25 \pm 1.83$ & $8(33.3)$ & $8.88 \pm 2.03$ & $0(0)$ & 0 & $0(0)$ & 0 \\
\hline Penicilliumsp & $8(38.1)$ & $6.63 \pm 1.30$ & $8(33.3)$ & $6.38 \pm 1.85$ & $8(27.6)$ & $9.63 \pm 2.55$ & $8(26.7)$ & $8.37 \pm 1.68$ \\
\hline Rhizopussp & $5(23.8)$ & $3.20 \pm 0.45$ & $8(33.3)$ & $3.13 \pm 0.84$ & $8(27.6)$ & $3.13 \pm 0.83$ & $8(26.7)$ & $3.37 \pm 1.06$ \\
\hline Curvulariasp & $0(0)$ & 0 & $0(0)$ & 0 & $8(27.6)$ & $3.63 \pm 0.52$ & $6(20.0)$ & $5.5 \pm 1.51$ \\
\hline Fusariumsp & $0(0)$ & 0 & $0(0)$ & 0 & $5(17.2)$ & $7.4 \pm 1.95$ & $0(0)$ & 0 \\
\hline Mucorsp & $0(0)$ & 0 & $0(0)$ & 0 & $0(0)$ & 0 & $8(26.6)$ & $2.75 \pm 0.46$ \\
\hline Total & $21(100)$ & $6.43 \pm 2.39$ & $24(100)$ & $6.13 \pm 2.87$ & $29(100)$ & $5.52 \pm 3.45$ & $30(100)$ & $4.97 \pm 2.59$ \\
\hline
\end{tabular}

Table 2 \& 3 Highlights the relative abundance of the mycotic load within the poultry feed samples as follows Aspergillus and Penicillium species recorded a relative abundance of $38.1 \%$ and $33.3 \%$ in the broiler starter and broiler finisher feed samples respectively, Penicillium and Rhizopus and each had a relative abundance of $27.6 \%$ in the chick mash while, abundance of $23.8 \%$ of Rhizopus in the broiler starter and $20.0 \%$ of Curvularia in the layers mash feed samples were observed.

Table 3: Anova.

\begin{tabular}{|c|c|c|c|c|c|c|}
\hline & & Sum of Squares & df & Mean Square & $\mathbf{F}$ & Sig \\
\hline \multirow{3}{*}{ SB } & Between Groups & 78.968 & 2 & 39.484 & 19.646 & 0 \\
\hline & With in Groups & 36.175 & 18 & 2.01 & & \\
\hline & Total & 115.143 & 20 & & & \\
\hline \multirow{3}{*}{ FB } & Between Groups & 133 & 2 & 66.5 & 24.234 & 0 \\
\hline & Within Groups & 57.625 & 21 & 2.744 & & \\
\hline & Total & 190.625 & 23 & & & \\
\hline \multirow{3}{*}{ SL } & Between Groups & 265.416 & 3 & 88.472 & 32.61 & 0 \\
\hline & Within Groups & 67.825 & 25 & 2.713 & & \\
\hline & Total & 333.241 & 28 & & & \\
\hline \multirow{3}{*}{ ML } & Between Groups & 154.217 & 3 & 51.406 & 32.799 & 0 \\
\hline & Within Groups & 40.75 & 26 & 1.567 & & \\
\hline & Total & 194.967 & 29 & & & \\
\hline
\end{tabular}

Figure 3 Highlights isolation frequencies of the mycotic genera isolated from the swine feed samples. Alternaria species had an isolation frequency of $100 \%$ in the bone meal, rice offal and soya beans feed samples. Fusarium species was predominantly isolated from the 'dusa' and brewer's residue 'burukutu' feed samples. Aspergillus species was predominant in the grain husk 'dusa', brewers residue 'burukutu 'and soya beans feed samples. Penicillium species predominated the soya beans and brewers 
residue 'burukutu' samples while Rhizopus and Mucor species predominanted the grain husk 'dusa' feed samples.

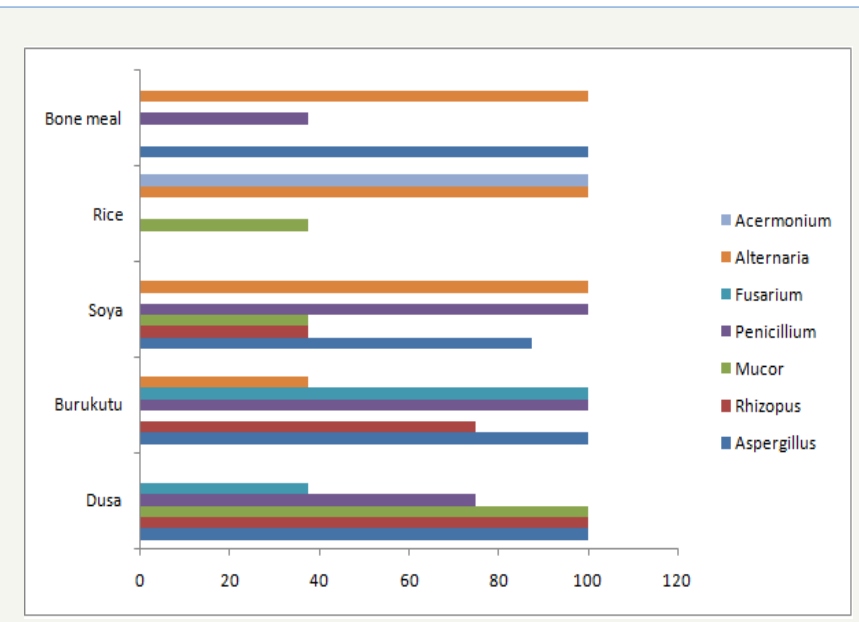

Figure 3: Isolation frequencies of different genera isolated from respective swine fee.

Figure 4 Highlights isolation frequencies of the mycotic genera isolated from the poultry feed samples Mucor, Rhizopus and Penicillium species where predominantly isolated from the layer mash feed samples with and isolation frequency of $100 \%$. However, a predominance of Curvularia was indicated in the chick mash. Broiler feed samples indicated infestation by Rhizopus, Penicillium and Aspergillus species. Figure 5 Highlights a section of mycotoxins isolated based on their wavelengths. Mycotoxins detected included aflatoxin B1 and B2, ochratoxins A and B, patulin, sterigmatocystin, zeralenone and citrinin.

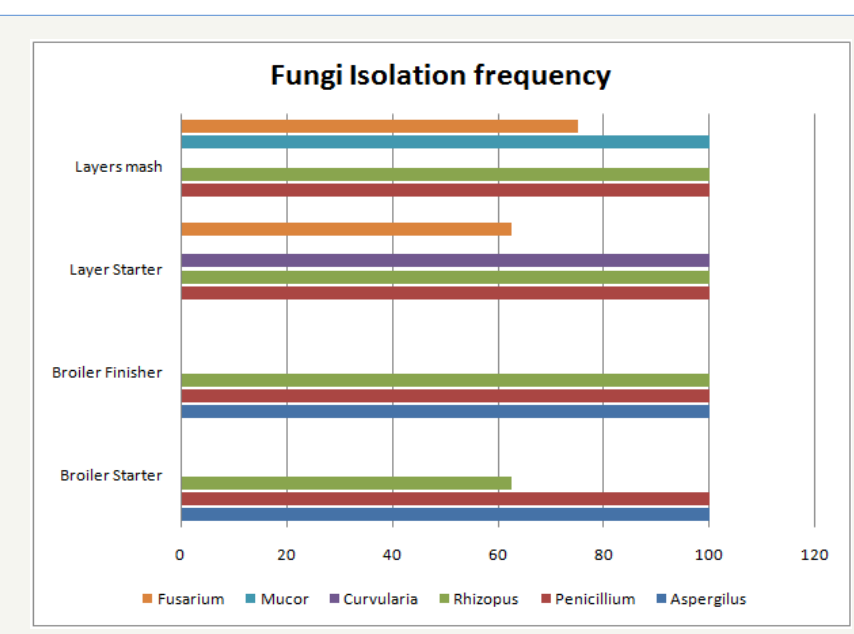

Figure 4: Isolation frequencies of different genera isolated from respective poultry feed.

\section{Discussion}

The quality of animal feed largely affects output. Productivity in animal breeding is often related to nutritional content of the feed therefore, emphasis is placed on improving nutrient quality of feed by addition of a variety of nutrient rich compounds and combination or rotation of different kinds of feed thus, it is not uncommon to have a form of feed rotation practice when breeding animal such as swine in the study environment. However, fed quality in terms of feed health and safety is a vital aspect to ensure a productive output Gremmel, 2004. Investigations in this study indicated that the swine and poultry feed samples were infested with a varied mycotic genera which included Aspergillus spp., Penicillium spp., Fusarium spp., Rhizopus spp., Alternaria spp., Acermonium spp., Mucor spp. and Curvularia spp. concurring with reports by Zain et al. [4]. Swine and poultry feed samples recorded highest mycotic abundance of $42.6 \%$ and $38.1 \%$ respectively of Aspergillus species. Magnoli et al. [10], reported relatively high isolation frequencies for Aspergillus flavus, Lebars-Baiely et al. [11] suggested that the genus Aspergillus possess thermophilic and thermo resistant characters thus, their tendencies to proliferate under storage conditions in tropical climates. Investigations from the study also showed that alflatoxins B1 and B2, ochratoxins A and B and Sterigamatocystin were detected at respective wavelengths (Figure 5).

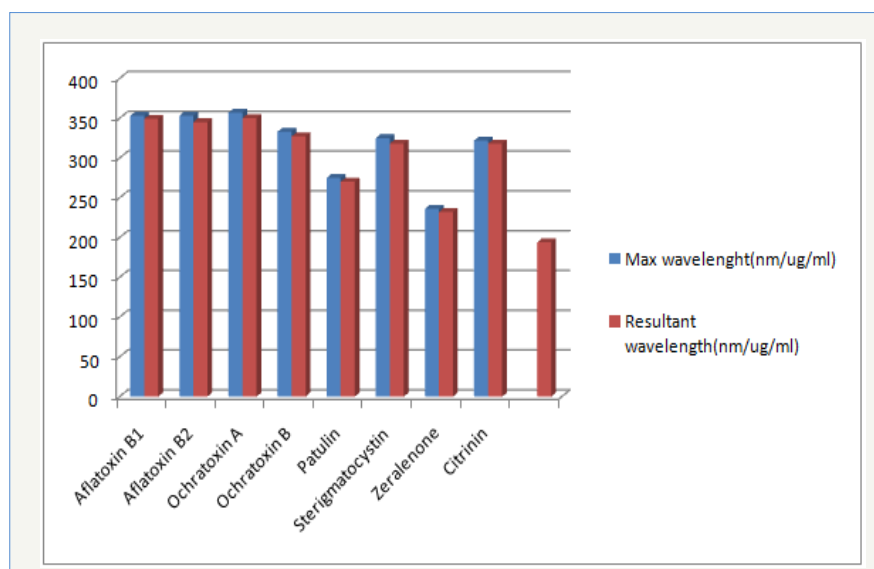

Figure 5: Wavelengths of isolated mycotoxin.

These mycotoxins have been implicated in a number of health conditions such as carcinogenesis, hypersensitivity reactions. Aspergillus spp. are also known to produce spores so their presence in animal feed is a concern to feed handlers as their spores have been implicated in respiratory inflammations, lung cancers and a reduced immunity; Rosa [2] reported ochratoxins produced by Aspergillus niger in substrates. Penicillium species was observed to proliferate in the poultry feed samples with an abundance of $33.1 \%$, the abundance of this species would account for the detection of mycotoxins such as citrinin and patulin. These mycotoxins have been implicated in Mycotic abundance of $26.6 \%$ as observed of Mucor spp. in layer mash samples and $42.1 \%$ was observed for Acremonium in the bone meal samples, Rippon [12] reported that Mucor and Clasdosporium species may cause mycotic abortions and allergic reactions in livestock and humans owing to respiratory and systemic transmissions. Fusarium spp. with an abundance of $36.1 \%$ was observed in the swine feed sample; the fungus has been associated with invasive mycosis and are associated with opportunistic infections in both man and animals Khosravi \& Gupta et al. [13] reported a dominance of $6 \%$ of Fusarium in feed samples, Gbore \& Egbunike [14] reported FB1 levels of $5000 \mu \mathrm{gkg}$ ${ }^{1}$ reduces sperm production. Fusarium has been implicated in the production of the mycotoxins zeralenone which have been reported to influence oestrogenic activity in swine, sheep and cattle [15]. In 
conclusion, results indicated relative mycotic load in both swine and poultry feed samples.

In spite of this, statistical analysis showed no significant difference was observed in the mycotic abundance within an eight week period. Arguments to extend sampling period may not hold sway because of high turnover in consumption of feed with respect to low feed production capacity as opposed to developed communities where there may be longer period of storage due to availability of feed raw material and mechanized production and surplus output. However, the heterogeneous form of feeding creates room for introduction of contamination as evident in the presence of mycotoxins in feed thus affecting shelf-life, it is safe to infer that there is deterioration in quality of feed within the sampling period in term of feed health and safety which is vital to productive output as it is necessary to ensure physiological functions and defense against diseases. To this end, it becomes imperative therefore to ensure that grains for feed are harvested at maturity, damage to produce is avoided at all stages of feed preparation, maintenance of even temperature during storage and use of extra caution when dealing with high moisture grain.

\section{References}

1. Castillo MD, Gonza'lez HHL, Marti'nez EJ, Pacin AM, Resnik SL (2004) Mycoflora and potential production of freshly harvested black bean from the Argentinean main production area. Mycopathologia 158(1): 107-112.

2. Rocha CAR, Palacios V, Combina M, Fraga ME, Rekson AD, et al. (2002) Potential ochratoxin A producers from wine grapes in Argentina and Brazil. Food Additives and Contaminants 19(4): 408-414.

3. D’Mello JPF, Macdonald AMC (1998) Mycotoxins. Animal Feed Science and Technology 69: 155-166.
4. Zain ME (2011) Impact of mycotoxins on humans and animals. Journal of Saudi Chemical Society 15: 129-144.

5. Dalcero A, Magnoli C, Luna M, Ancasi G, Reynoso MM, et al. (1998) Mycoflora and naturally occurring mycotoxins in poultry feeds in Argentina. Mycopathologia 141(1): 37-43.

6. Abbasa HK, Cartwrightb RD, Xiec W, Shier WT (2006) Aflatoxin and fumonisin contamination of corn (maize, Zea mays) hybrids in Arkansas. Crop Protection 25: 1-9.

7. Pitt JI, Hocking AD (1997) Fungi and Food Spoilage. ( $2^{\text {nd }}$ edn) Chapman \& Hall, Cambridge, UK, p. 593

8. Klich MA (2002) Identification of Common Aspergillus Species. Centraal bureauvoor Schimmel cultures, Utrecht, The Netherlands, pp. 116.

9. Soares LMV, Rodriguez-ADB (1989) Survey of aflatoxins, ochratoxinA, zearalenone and sterigmatocystin in some Brazilian foods by using multi-toxin thin layer chromatographic method. Journal Association Official Method of Analisys, Washington 72(1): 22-26.

10. Magnoli C, Astoreca A, Ponsone L, Chiacchiera S, Dalcero A, et al. (2006) Ochratoxin A and the occurrence of ochratoxin A-producing black aspergilli in stored peanut seeds from Co' rdoba, Argentina. Journal of the Science of Food and Agriculture 86(14): 2369-2373.

11. Lebars-BS, Bailly JD, Brugere H (1999) Accidents de fabrication dus aux moisissures en fromagerie. Rev Méd Vét 50(5): 413-430.

12. Rippon JW (1988) Medical mycology. ( $2^{\text {nd }}$ edn) WB Saunders company, Chicago Illinois, USA, pp: 640-641.

13. Gupta AK, Baram R, Summerbell RC (2000) Fusarium infections of the skin. Current Opinion in infectious Diseases 13(2): 121-128.

14.Gbore FA, Egbunike GN (2008) Testicular and epididymal sperm reserves and sperm production of pubertal boars fed dietary fumonisin B1. Animal Reproduction Science Amsterdam 105(3-4): 392-397.

15. Zinedine A, Miguel SJ, Manes J (2007) Review on the toxicity, occurenece, metabolism, detoxification, regulations and intake of Zeralenone: an oestrogenic mycotoxins. Food and Chemical Toxicology 45(1): 1-11.

\section{Your subsequent submission with Crimson Publishers will attain the below benefits}

- High-level peer review and editorial services

- Freely accessible online immediately upon publication

- Authors retain the copyright to their work

- Licensing it under a Creative Commons license

- Visibility through different online platforms

- Global attainment for your research

- Article availability in different formats (Pdf, E-pub, Full Text)

- Endless customer service

- Reasonable Membership services

- Reprints availability upon request

- One step article tracking system 